\title{
Methamphetamine-induced changes in the striatal dopamine pathway in $\mu$-opioid receptor knockout mice
}

\author{
Sang Won Park ${ }^{1 *}$, Xine Shen², Lu-Tai Tien ${ }^{3}$, Richard Roman ${ }^{1}$ and Tangeng Ma ${ }^{1}$
}

\begin{abstract}
Background: Repeated exposure to methamphetamine (METH) can cause not only neurotoxicity but also addiction. Behavioral sensitization is widely used as an animal model for the study of drug addiction. We previously reported that the $\mu$-opioid receptor knockout mice were resistant to METH-induced behavioral sensitization but the mechanism is unknown.

Methods: The present study determined whether resistance of the $\mu$-opioid receptor ( $\mu$-OR) knockout mice to behavioral sensitization is due to differential expression of the stimulatory $\mathrm{G}$ protein $\alpha$ subunit (Gas) or regulators of G-protein signaling (RGS) coupled to the dopamine D1 receptor. Mice received daily intraperitoneal injections of saline or METH (10 mg/kg) for 7 consecutive days to induce sensitization. On day 11 (following 4 abstinent days), mice were either given a test dose of METH $(10 \mathrm{mg} / \mathrm{kg})$ for behavioral testing or sacrificed for neurochemical assays without additional METH treatment.

Results: METH challenge-induced stereotyped behaviors were significantly reduced in the $\mu$-opioid receptor knockout mice when compared with those in wild-type mice. Neurochemical assays indicated that there is a decrease in dopamine D1 receptor ligand binding and an increase in the expression of RGS4 mRNA in the striatum of METH-treated $\mu$-opioid receptor knockout mice but not of METH-treated wild-type mice. METH treatment had no effect on the expression of Gas and RGS2 mRNA in the striatum of either strain of mice.
\end{abstract}

Conclusions: These results indicate that down-regulation of the expression of the dopamine D1 receptor and upregulation of RGS4 mRNA expression in the striatum may contribute to the reduced response to METH-induced stereotypy behavior in $\mu$-opioid receptor knockout mice. Our results highlight the interactions of the $\mu$-opioid receptor system to METH-induced behavioral responses by influencing the expression of RGS of dopamine D1 receptors.

Keywords: Amphetamine, ? $\mu$ ?-opioid receptor, addiction, dopamine receptors

\section{Background}

Methamphetamine (METH) is a highly abused CNS stimulant with high reward properties that leads to compulsive drug seeking behavior $[1,2]$. The mechanism of the additive properties to METH remains to be determined. Repeated administration of METH results in behavioral sensitization characterized by persistent hyperlocomotor activity and stereotyped behaviors [3,4]. Animals remain sensitized for many weeks, suggesting

\footnotetext{
* Correspondence: spark@umc.edu

'Department of Pharmacology and Toxicology, University of Mississippi

Medical Center, Jackson, MS 39216, USA

Full list of author information is available at the end of the article
}

that the development of sensitization involves long-lasting neuronal adaptations [5]. The neural alterations underlying behavioral sensitization are also thought to contribute to mimic changes associated with the compulsive drug seeking behavior. Thus, behavioral sensitization is widely used as an animal model for the study of drug addiction [5-8] and it is extremely important to find therapeutic agents for behavioral sensitization to psychostimulants.

The dopamine system is generally considered a main target for amphetamines to stimulate locomotor activity and stereotyped behaviors. The nigrostriatal dopaminergic pathway consists of dopaminergic neurons of the 
substantia nigra that innervate the striatum [9] that is intimately linked to the stereotyped behaviors produced by psychomotor stimulants [10]. It is well known that an increase in dopaminergic activity in the central nervous system (CNS) plays a central role in induction and expression of behavioral sensitization by psychomotor stimulants. For example it is known that activation of dopamine receptors is required for the expression of behavioral sensitization by METH [11]. METH stimulates the release of dopamine from dopaminergic neurons and activates dopamine receptors [12]. Dopamine receptors as members of the $\mathrm{G}$ protein-coupled receptor (GPCR) superfamily elicit a variety of cellular and behavioral responses through various signaling pathways to induce behavioral effects [13]. Regulators of G-protein signaling (RGS) proteins negatively regulate GPCR signaling, changes in RGS protein levels in the brain are thought to modulate the intensity and duration of signaling of cognate receptors [14]. The expression of several RGS proteins in the brain is rapidly altered in response to psychostimulants [15]. In addition there is growing evidence that exposure to amphetamine-like stimulants influences the expression of dopamine receptors, G-proteins and RGS in neurons that may contribute to stimulant-mediated behavioral responses [16]. Chronic administration of dopamine D1 agonist SKF 38393 results in enhanced behavioral responses to subsequent administration of a variety of dopamine agonists $[17,18]$. Others have found that stereotypic behavior in response to amphetamine administration is associated with increased expression of dopamine D1 receptors [19] and hypersensitivity of adenylate cyclase to dopamine stimulation which is blocked by the dopamine D1 antagonist SCH 23390 [20].

It is also clear that there are extensive anatomical and functional interactions between the dopaminergic system and other neuronal pathways. For example both the opioidergic and glutamatergic systems contribute to the development and maintenance of behavioral sensitization to METH [21]. Endogenous opioid systems have been found to play important roles in reward, positive reinforcement, and additive effects on drugs of abuse [22-24]. The endogenous opioid systems consist of a variety of endogenous opioid peptides and receptors. At least three opioid receptor subtypes $(\delta, \mu$, and $\kappa)$ are currently recognized [25]. Enkephalins have high affinity for $\mu$ - and $\delta$ - opioid receptors whereas dynorphins have high affinity for $\kappa$-opioid receptors. It has been reported that amphetamines induce an increase in expression of the opioid peptide enkephalin precursor preproenkephalin mRNA in rodent striatum [26]. No behavioral sensitization to amphetamine was detected in the enkephalin knockout mice [27]. We also reported that $\mu$-opioid receptor $(\mu-\mathrm{OR})$ knockout mice were less sensitive to the development of behavioral sensitization to METH [28]. However, it remains to be determined how $\mu$-OR contribute to METH-induced behavioral responses. The present study examined whether METH exposure causes differential changes in the expression of stimulatory $\mathrm{G} \alpha$ (Gos; subunit coupled to dopamine D1 receptors) or RGS associated with dopamine D1 receptors in the CNS that may contribute to the resistance to METH-induced behavioral sensitization in $\mu$-OR knockout mice.

\section{Materials and methods}

\section{Animals and drug treatments}

The $\mu$-OR knockout mice were originally developed by Loh et al. [29] on a C57/BL6 and 129/Ola hybrid genetic background. Our colony was maintained as heterozygotes by brother sister mating in the Laboratory Animal Facility of the University of Mississippi Medical Center (UMMC). All procedures were approved by Institutional Animal Care and Use Committee of the UMMC, and performed in compliance with the NIH Guide for the Care and Use of Laboratory Animals. Adult male wild-type and $\mu$-OR knockout mice were used in this study. $\mu$-OR knockout and wild-type mice ( $\mathrm{n}=12$ for each genotype) were given METH $(10 \mathrm{mg} / \mathrm{kg}$, i.p.) once a day for 7 consecutive days to induce sensitization in order to investigate METHevoked behavioral response. This dose was chosen on the basis of previous studies indicating that it was the dose that induced stereotyped behavioral sensitization to subchronic administration of METH in mice [28,30]. On day 11 , after a 4 day drug washout period, the sensitized mice were challenged with a i.p. injection of METH $(10 \mathrm{mg} / \mathrm{kg})$. Stereotyped behaviors were monitored for $30 \mathrm{~min}$ before and for $5 \mathrm{hrs}$ after the injection to evaluate the behavioral responses.

The behavior of mice was monitored in a Plexiglas ${ }^{\circledR}$ box equipped with a CCD camera and recorded on video tape, which was subsequently analyzed by a trained observer. The intensity of stereotyped activity was scored on 4-point scale (0 - normal behavior, 1 - periodic sniffing, 2 - continuous sniffing, 3 - continuous sniffing, periodic licking or gnawing, 4 - continuous licking or gnawing) as described by Costall and colleagues [31].

Parallel experiments were performed in another group of wild-type and $\mu$-OR knockout mice to assess changes in the expression of dopamine receptors and mRNA in the brain. These animals were sensitized using the same 7 day exposure to METH or vehicle. After a 4 day drug-washout period, the animals were decapitated and the brains collected and frozen in liquid nitrogen. Coronal sections (14$20 \mathrm{~mm}$ thick) were cut using a cryostat (Tissue-Tek, cyro 2000) at $-20^{\circ} \mathrm{C}$, thaw-mounted on gelatin-coated slides and stored at $-80^{\circ} \mathrm{C}$ for autoradiography and in situ hybridization analysis. 


\section{Autoradiography}

Dopamine D1 receptor levels were measured using radiolabeled ligand binding and autoradiography as previously described by Qian et al. [32]. Briefly, brain sections were pre-incubated at $4^{\circ} \mathrm{C}$ for $30 \mathrm{~min}$ in a $50 \mathrm{mM}$ Tris-HCI buffer (pH 7.4) containing $120 \mathrm{mM} \mathrm{NaCl}, 5 \mathrm{mM} \mathrm{KCl,} 2 \mathrm{mM}$ $\mathrm{CaCl}_{2}$, and $1 \mathrm{mM} \mathrm{MgCl}$, and then incubated for $60 \mathrm{~min}$ with $1.6 \mathrm{nM}$ of the labeled dopamine D1 receptor antagonist $\left[{ }^{3} \mathrm{H}\right] \mathrm{SCH} 23390$ at room temperature. Other sections were incubated with $30 \mu \mathrm{M}$ of the dopamine D1 receptor ligand $( \pm)$ SKF38393 [33] to control for nonspecific binding. The labeled brain sections as well as a set of $\left[{ }^{3} \mathrm{H}\right]$ impregnated plastic standards $\left(\left[{ }^{3} \mathrm{H}\right]\right.$ Microscale, Amersham Life Science) were placed on Kodak BioMax MS film for 3 weeks $\left(-80^{\circ} \mathrm{C}\right)$. The films were developed, and then analyzed using a scanning densitometer and Image Quant 3.3 program (Molecular Dynamics; Sunnyvale, CA).

\section{In Situ Hybridization}

The expression of Gas, RGS2, and RGS4 mRNAs in the brain were determined using in situ hybridization. The focus of the present experiment was to examine changes in the expression of Gas, RGS2, and RGS4 in the striatum of the mouse brain. We and others have used in situ hybridization techniques [34-36] to successfully study gene expression for a wide variety of gene products. The technique relies on the specificity of the probe. Oligonucleotide probes complementary to mRNAs encoding mouse Gas (5'-GCAAAGCAGCGCCTGCCTGCCCGTCTGCCTG CCGCCGCC-3') [34], RGS2 (5'-GGGCTCCGTGGT GATCTGTGGCTTTTTACATAAG-3'), and RGS4 (5'GCTGG AAGGATTGGTCAGGTCAAGATAGAATCGAG-3') [35] were 3' end labeled with $\left[{ }^{35} \mathrm{~S}\right.$ ]dATP using terminal deoxynucleotidyltransferase (PerkinElmer Life Sciences, Shelton, CT) and in situ hybridization was performed as described earlier [36]. The probes used were identical to those described by Tervonen et al. [35] who verified that they specifically bound to RGS2 and RGS4 and Przewlocka et al. [34] who tested the Gas probe. We also BLASTED the sequence of the probes against all of the sequences in GENBANK and found that they exhibited a 100\% match to the intended target. Only the RGS4 probe exhibited any significant homology (17 of $35 \mathrm{bp}$ ) to another target, i.e. the presenilin-2 gene. However, given the limited numbers of complementary base pairs, it is highly unlikely that the RGS4 would bind to this target at the hybridization temperature used of $38^{\circ} \mathrm{C}$. Moreover, we also performed appropriate control experiment to exclude non-specific binding. The labeled slides were exposed to Kodak BioMax MR films for 5 days for Gas or 11 weeks for RGS2 and RGS4, and the films were developed and fixed. The quantification of the autoradiogram was performed using the Image Quant software (Molecular Dynamics, Sunnyvale, CA).

\section{Statistical Analysis}

Data are expressed as mean values \pm SEM. The significance of differences in mean values was analyzed using a $t$ test (stereotyped behaviors) or a two-way ANOVA followed by a Student-Newman-Keuls post hoc test. A $P<0.05$ was considered to be significant.

\section{Results}

METH-evoked stereotyped behaviors in METH-sensitized wild-type and $\mu$-OR knockout mice

Administration of METH in sensitized wild-type animals produced stereotyped behaviors, characterized by continuous sniffing and licking that persisted for about 5 hours. In the $\mu$-OR knockout mice the cumulative score of stereotyped behaviors was significantly lower than in the wild-type mice (Figure 1).

$\left[{ }^{3} \mathrm{H}\right] \mathrm{SCH} 23390$ binding in the striatum of METH-sensitized wild-type and $\mu$-OR knockout mice

Representative autoradiograms of $\left[{ }^{3} \mathrm{H}\right] \mathrm{SCH} 23390$ binding in the brain of wild-type and $\mu$-OR knockout mice are presented in Figure 2. High levels of $\left[{ }^{3} \mathrm{H}\right] \mathrm{SCH} 23390$ binding were seen in the striatum. Basal binding of $\left[{ }^{3} \mathrm{H}\right]$ $\mathrm{SCH} 23390$ in the striatum was not significantly different between wild-type and $\mu$-OR knockout mice treated with saline. Repeated METH treatment had no significant effect on D1 receptor binding in wild type mice. In contrast, the binding of $\left[{ }^{3} \mathrm{H}\right] \mathrm{SCH} 23390$ was markedly reduced in the $\mu$-OR knockout in mice sensitized by repeated exposure to METH.

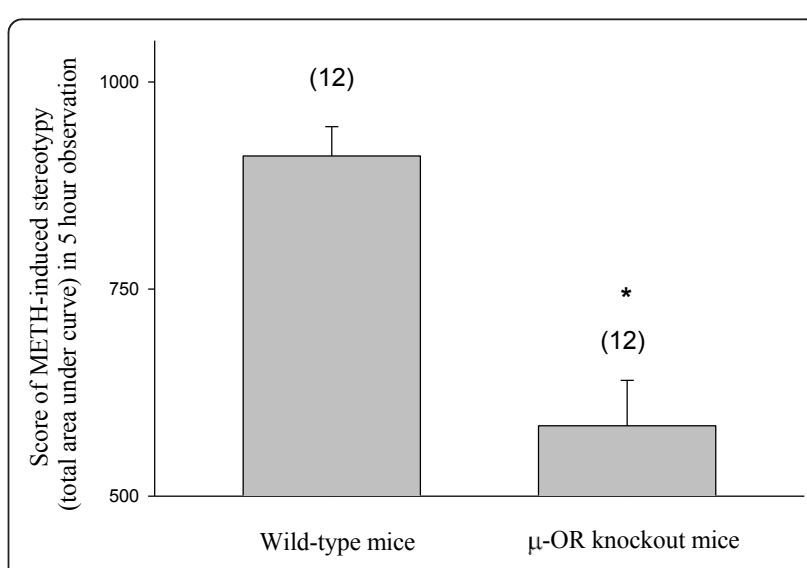

Figure $1 \mathrm{METH}$ (10 mg/kg)-evoked stereotyped behaviors in wild-type and $\mu$-OR knockout mice that were exposed to METH for 7 days. METH (10 mg/kg)-evoked stereotyped behaviors in wild-type and $\mu$-OR knockout mice that were exposed to METH for 7 days. Mean values \pm SEM are presented. Numbers in parentheses represent the number of animals studied. ${ }^{*}$ indicates a significant difference $(P<0.05)$ from the corresponding value in METH-sensitized wild-type mice. 


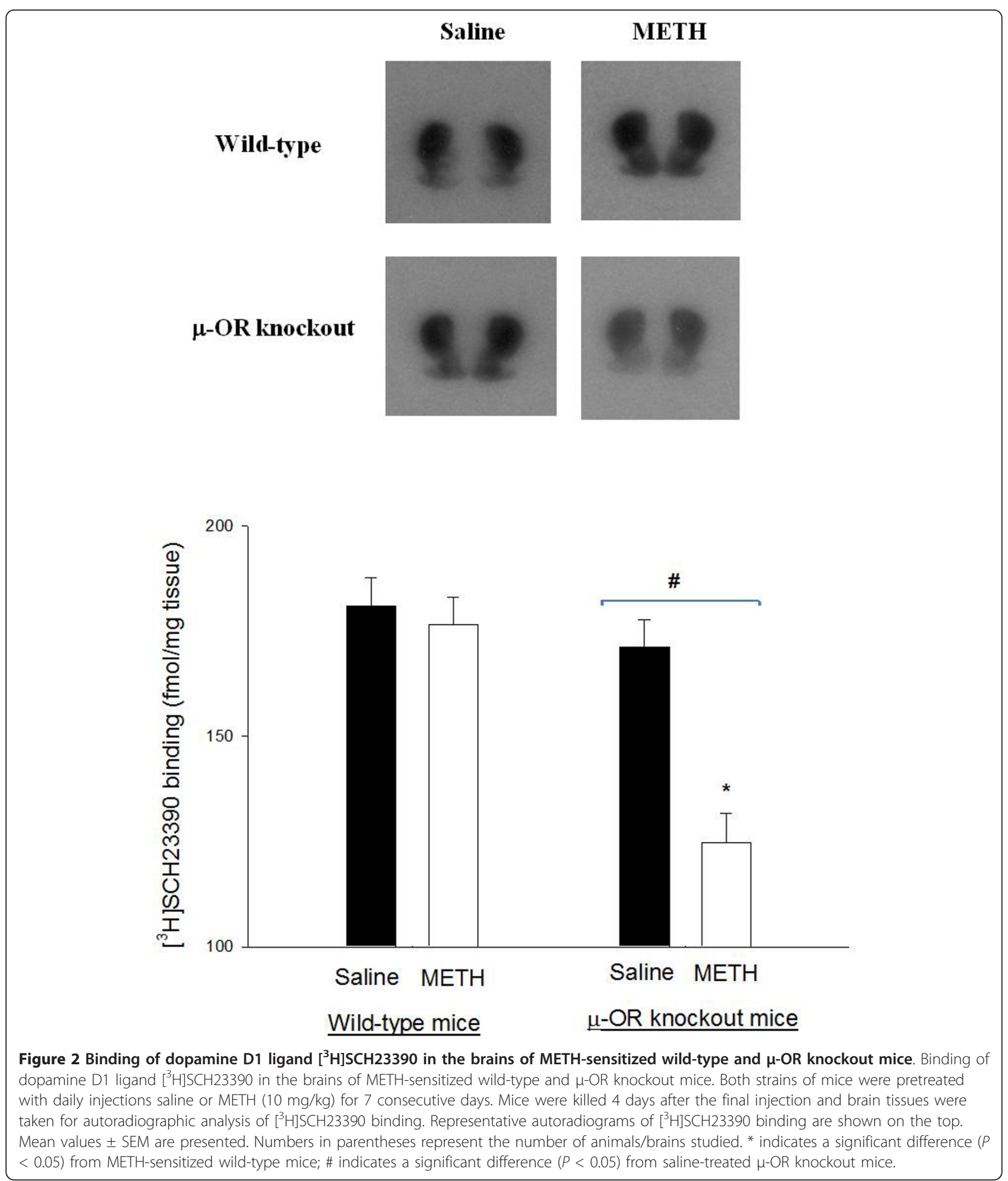

The expression of the stimulatory $\mathrm{G}$ protein $\alpha$ subunit (Gos) mRNA in the striatum of METH-sensitized wild-type and $\mu$-OR knockout mice

Representative autoradiograms of in situ hybridization of Gas mRNA in the brain of wild-type and $\mu$-OR knockout mice are presented in Figure 3. Gas mRNA is widely expressed in most brain areas including striatum and cerebral cortex. The expression of Gas in the striatum was similar in both wild-type and $\mu$-OR knockout animals treated with saline. METH treatment did not alter the 


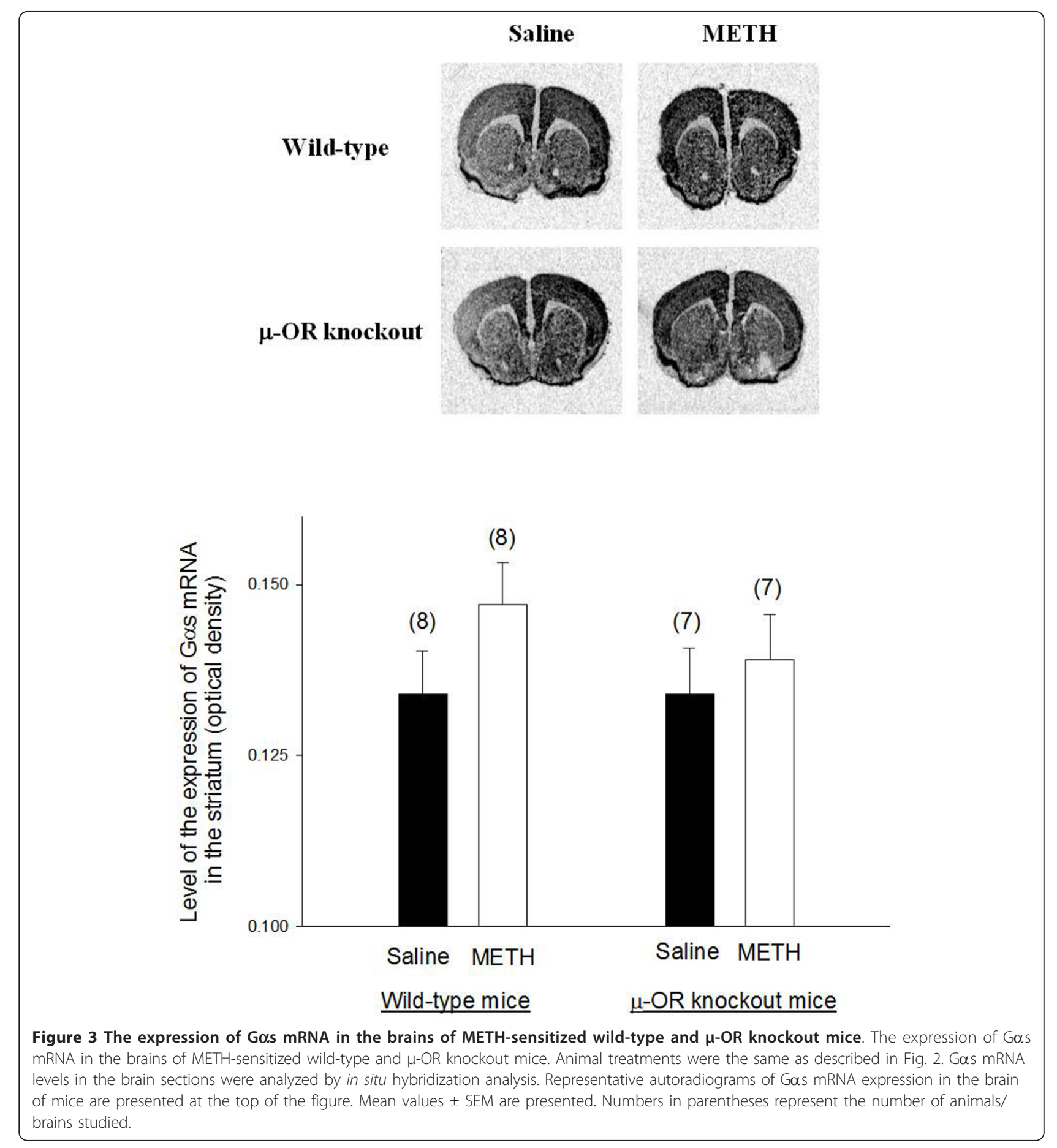

expression of Gas mRNA in the striatum wild type mice or in $\mu$-OR knockout mice.

The expression of RGS2 and RGS4 mRNAs in the striatum of METH-sensitized wild-type and $\mu$-OR knockout mice

Representative autoradiograms of in situ hybridization signals for RGS2 and RGS4 mRNAs in the brain of wild-type and $\mu$-OR knockout animals are presented in Figures 4 and 5, respectively. Both of RGS2 and RGS4 mRNAs were highly expressed in the striatum. There was no significant difference in the expression of RGS2 mRNA in the striatum of $\mu$-OR knockout or wild-type mice treated with saline or METH. Basal expression of RGS4 was also similar in $\mu$-OR knockout and wild-type mice treated with saline. However, the expression of RGS4 mRNA in the striatum increased in $\mu$-OR knockout mice treated with METH but 


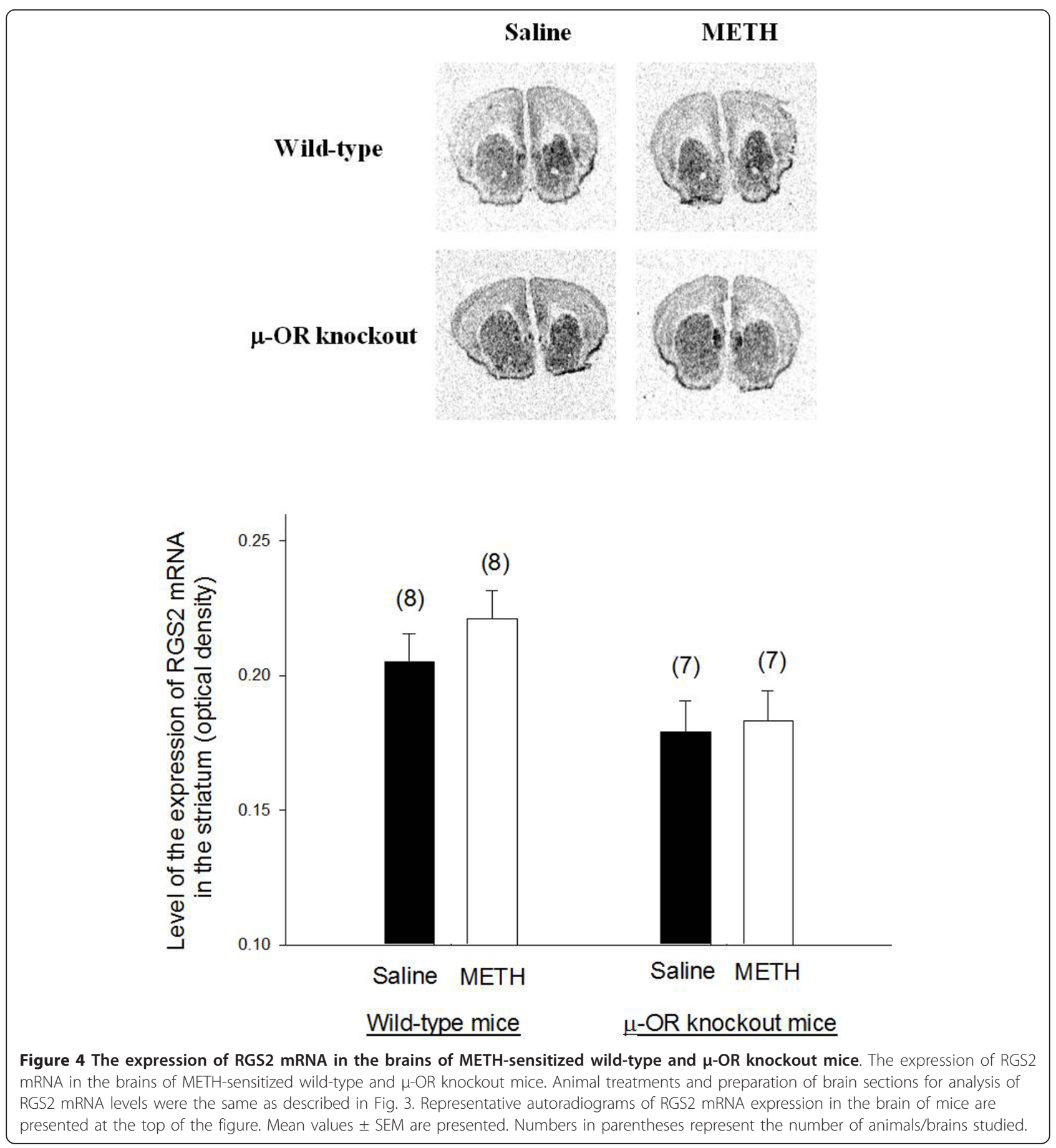

remained unchanged in wild-type mice sensitized with METH.

\section{Discussion}

The CNS stimulant-METH induces behavioral sensitization which is associated persistent hyperlocomotor activity and stereotyped behaviors. Behavior sensitization is a widely used in rodents model for study of drug addiction and drug seeking behaviors [5,37]. In the present study we confirmed previous finding that $\mu$-OR knockout mice demonstrate significantly decreased behavioral sensitization to METH as compared with wild-type mice. This was associated with a significant reduction in dopamine D1 receptor density in the striatum of approximately $30 \%$ in $\mu$-OR knockout mice when compared to wild-type mice exposed to METH. By way of contrast, METH had 


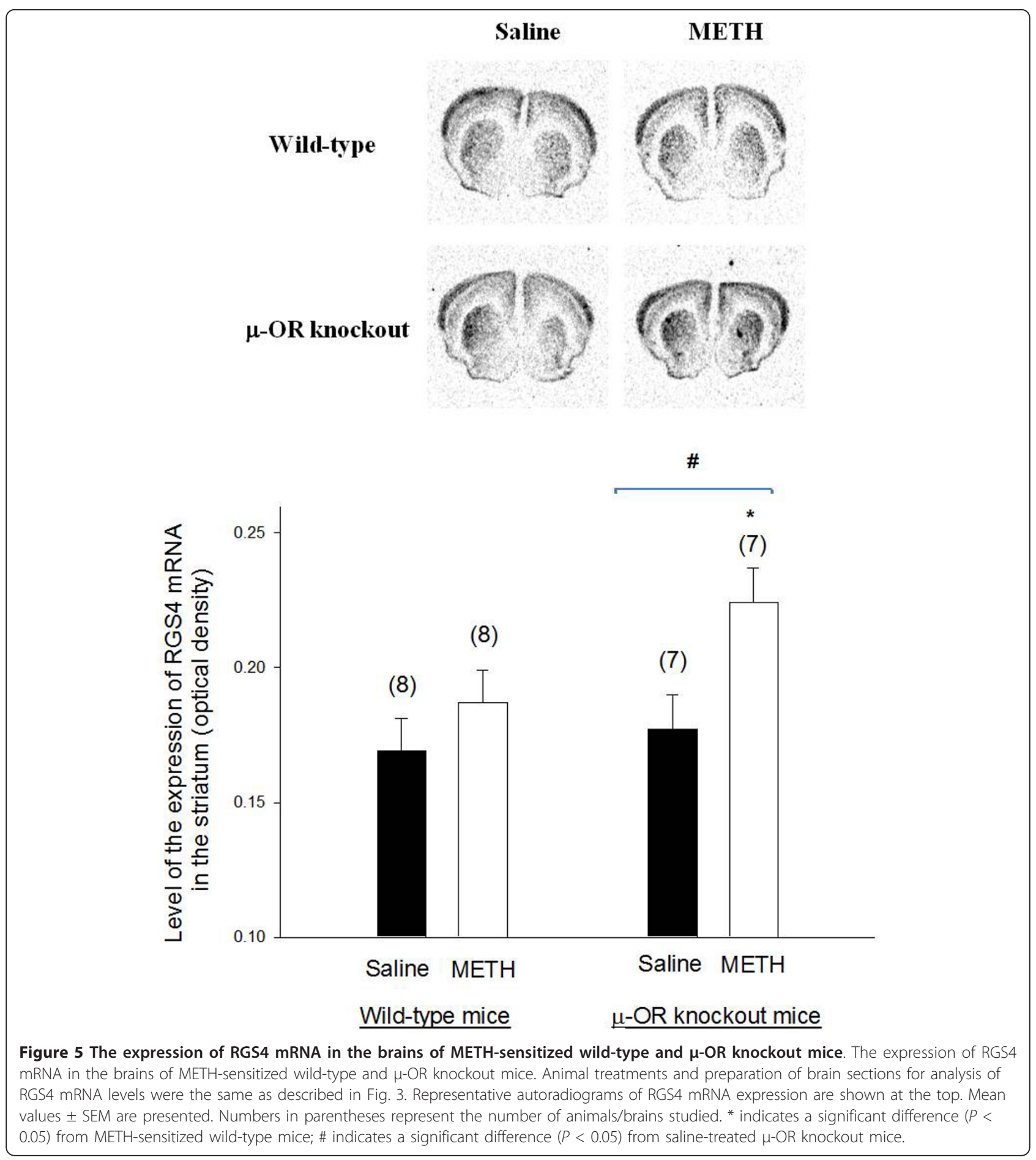

no effect on dopamine D1 receptor density in the striatum of wild-type mice.

We also found that the expression of Gas mRNA was unaltered by METH exposure in wild type or knockout mice, as was the expression of mRNA of the regulator of G-protein signaling, RGS2. However, the expression of RGS4 mRNA was significantly increased in the striatum of METH treated $\mu$-OR knockout mice as compared to saline treated controls, whereas METH treatment had no effect on RGS4 mRNA in wild-type controls. These data suggest that in $\mu$-OR knockout mice dopamine D1 receptor function in the striatum can be more readily down-regulated than in wild- type mice after repeated METH exposure. This may, in part, 
explain the decreased behavioral sensitization observed after METH treatment of $\mu$-OR knockout mice.

Dopamine is an important neurotransmitter in the CNS where it plays essential roles in numerous physiological, neuronal, and behavioral processes. One important component of the pathways in the CNS is the nigrostriatal dopaminergic system, projecting from the substantia nigra to the striatum (putamen and caudate nucleus) that is known to be crucial for the induction of stereotyped behaviors [10]. Previously, we and others have performed dose response studies and found that $2.5 \mathrm{mg} / \mathrm{kg} \mathrm{METH}$ is sufficient to elicit a locomotor response $[28,38]$ but higher doses $(10 \mathrm{mg} / \mathrm{kg})$ are needed to induce behavioral sensitization to METH $[28,30]$. Repeated stimulation of dopamine receptors with agonists has been shown to cause down-regulation in expression of these receptors [39]. As an indirect dopamine receptor agonist, METH is known to stimulate the release and inhibit reuptake of dopamine from synaptic cleft [40], increasing extracellular dopamine levels and activating postsynaptic striatal dopamine receptors. Thus, repeated METH exposure lead to down regulation of the expression of dopamine receptors in the striatum. In other studies, we found that METH $(10 \mathrm{mg} / \mathrm{kg})$ was associated with decreased tyrosine hydroxylase (the rate limiting enzyme of dopamine synthesis) in wild-type mice but not in the $\mu$-OR knockout mice. These results along with our present findings indicate that the changes of dopaminergic system in mice chronically exposed to METH is related to a decrease in the expression of the enzyme involved in the synthesis of dopamine and its actions on dopamine D1 receptors rather than to the loss of dopaminergic neurons. Nonetheless, these data demonstrate that the $\mu$-opioid receptor modulates the response of dopamine neurons to METH.

There are two types of dopamine receptors in the striatum: D1 and D2. Striatonigral neurons largely express dopamine D1 receptors whereas most striatopallidal neurons express dopamine D2 receptors [41]. Although concurrent activation of dopamine D1 and D2 receptors is thought to be required for the full induction of stereotyped behaviors [11], activation of dopamine D1 receptors is primarily responsible for the induction of dopamine-mediated stereotypy [42]. Therefore, the down regulation of dopamine D1 receptor we found in the striatum of METH-sensitized $\mu$-OR knockout mice compared with wild-type is consistent with the view that this contributes to the less of METH-induced stereotyped behaviors in this strain of mice. Surprisingly, METH exposure in wild-type mice did not down-regulate D1 dopamine receptors. Previously our lab reported that quantitative autoradiographic analysis of striatum and nucleus accumbens showed that METH treatment leads to a decrease in dopamine D1 receptor ligand binding in $\mu$-OR knockout mice but not in wildtype mice at low concentration $(0.4 \mathrm{nM})$ of dopamine D1 receptor antagonist SCH 23390 [36]. This suggests that interactions between opiodergic receptors/neurons and neurons of the nigrostriatal pathway occur that stabilize receptor density. These interactions between these pathways and the mechanisms involved deserve further study.

Chronic treatment (2-3 weeks) with dopamine D1 receptor antagonist $\mathrm{SCH} 23390$ has been reported to increase the expression of mRNA for preproenkephalin in the rat striatum $[43,44]$. Recently, we found that there was an increase in expression of preproenkephalin mRNA in the nucleus accumbens and striatum in METH-sensitized wild-type mice but not in $\mu$-OR knockout mice [36]. Also, METH induced hyperlocomotor activity at low doses and stereotyped behaviors at high doses in wild-type mice [28] but not in $\mu$-OR knockout mice. These results indicate that a decrease in striatal and nucleus accumbens D1 receptors in METH-sensitized $\mu$-OR knockout mice is associated with a decrease in the behavioral response in these animals. The exact mechanism of how the $\mu$-opioid system modulates dopaminergic neurotransmission and thus influences METH-produced behavioral responses is unclear. Based on data in the literature, however, it can be proposed that METH-induced changes in G protein signaling and RGS proteins might play a role in the development of behavioral sensitization to the drug.

Dopamine receptors are members of the GPCR family. Stimulation of the dopamine D1 receptors activates adenylyl cyclase via Gas, increasing intracellular cAMP that activates cAMP-dependent protein kinase $A$ and its down-stream effectors [45]. There is evidence that G protein signaling may be disrupted in drug addiction and neuropsychiatric disorders $[46,47]$. For example, postmortem brain studies have revealed increased levels of Gas in bipolar disorder, a type of mood disorder with unknown etiology as well as being inducible by CNS stimulants [48]. Elevation of Gas levels is thought to enhance signaling through the dopamine D1 receptor and contribute to dopamine D1 receptor activationmediated behavioral responses [49]. Therefore, we examined the expression of Gas mRNA in the striatum of METH-sensitized mice. The results of the present study indicate that the expression of Gas mRNA in the striatum was not altered by repeated METH exposure in either $\mu$-OR knockout or wild-type mice.

Another possible effect of repeated METH exposure is to alter the activity of the $\mathrm{G} \alpha$ protein. The primary regulators of GTPase activity of G $\alpha$-subunits are RGS proteins that rapidly terminate receptor-activated G $\alpha$ GTP signaling by accelerating the hydrolysis of GTP to GDP [50,51]. More than 30 mammalian RGS proteins have been identified [50,52]. Gene expression studies demonstrate that RGS2 and RGS4 are avidly expressed in cortex, striatum, and several thalamic regions of the brain $[53,54]$. The available evidence suggests that activation of 
dopamine D1 and D2 receptors in the striatum of rat is coupled to RGS2 and RGS4 [55].

Amphetamine-like stimulants alters RGS mRNA expression in the brain and triggers GPCR signaling [56-58]. There are several lines of evidence that acute or repeated treatment with amphetamine modulates druginduced behavioral and changes in gene and protein expression of RGS4 in prefrontal cortex and dorsal striatum [59-61]. RGS4 mRNA was decreased in the striatum lasting from 1 to $6 \mathrm{hr}$ after acute amphetamine [62]. RGS4 may belong to the growing family of factors regulating convergence of dopamine signaling in the striatum [63].

In the present study, METH $(10 \mathrm{mg} / \mathrm{kg})$ exposure had no influence on the expression of RGS2 mRNA in the striatum of either $\mu$-OR knockout or wild-type mice. However, there was a higher expression of RGS4 mRNA in the striatum of METH-sensitized $\mu$-OR knockout mice but not of wild-type mice. Increased expression of RGS4 is consistent with a reduction in signaling via dopamine D1 receptors in the striatum that may already be reduced due to the decreased density of dopamine D1 receptors in METH treated $\mu$-OR knockout mice. Down-regulation of dopamine D1 receptor binding in combination with increased RGS4 mRNA levels is consistent with diminished dopamine D1 receptor function in METH-exposed $\mu$-OR knockout mice that would decrease the occurrence of behavioral sensitization.

\section{Conclusions}

In conclusion, the present study indicates that knockout of $\mu$-OR in mice reduces their sensitivity to METHinduced stereotyped behaviors. Down-regulation of the expression of the dopamine D1 receptor in combination with up-regulation of the expression of RGS4 in the striatum of METH-sensitized $\mu$-OR knockout mice may contributes to the resistance to the behavioral responses to METH in this strain. The results suggest that the $\mu$ opioid system and RGS proteins might be targets for the development of drugs that might reduce the reward potential and compulsive drug seeking behavior in METH abusers.

\section{Acknowledgements}

The authors gratefully thank Drs. Jerry M. Farley and lan A. Paul at UMMC for their valuable comments on this study and Dr. Horace $\mathrm{H}$. Loh at the University of Minnesota Medical School for providing with $\mu$-OR knockout mice.

\section{Author details}

'Department of Pharmacology and Toxicology, University of Mississippi Medical Center, Jackson, MS 39216, USA. ²Department of Physiology, Medical school, Soochow University, Jiangsu, P.R China. ${ }^{3}$ School of Medicine, Fu Jen Catholic University, Taipei, Taiwan.

\section{Authors' contributions}

SP carried out the in situ hybridization studies, performed the statistical analysis, and drafted the manuscript. XS participated in the animal treatment and study. LT carried out the ligand binding assay. RR participated in the data analysis and editing the manuscript. TM conceived the study and supervised the study. All authors read and approved the final manuscript.

\section{Competing interests}

The authors declare that they have no competing interests.

Received: 27 June 2011 Accepted: 10 November 2011 Published: 10 November 2011

\section{References}

1. Volkow ND: Communities across the country are trying to respond to increased abuse of methamphetamine, a powerfully addictive stimulant. NIDA webpage: message from the Director on Methamphetamine abuse 2005 [http://www.nida.nih.gov/about/welcome/messagemeth405.html].

2. Reiner BC, Keblesh JP, Xiong H: Methamphetamine abuse, HIV infection, and neurotoxicity. Int J Physiol Pathophysiol Pharmacol 2009, 25:162-179.

3. Shippenberg TS, Heidbreder C: Sensitization to the conditioned rewarding effects of cocaine: pharmacological and temporal characteristics. J Pharmacol Exp Ther 1995, 273:808-815.

4. Bartlett E, Hallin A, Chapman B, Angrist B: Selective sensitization to the psychosis-inducing effects of cocaine: a possible marker for addiction relapse vulnerability? Neuropsychopharmacology 1997, 16:77-82.

5. Steketee JD, Kalivas PW: Drug Wanting: Behavioral Sensitization and Relapse to Drug-Seeking Behavior. Pharmacol Rev 2011, 63:A-R.

6. Robinson TE, Berridge KC: The neural basis of drug craving: an incentivesensitization theory of addiction. Brain Res Brain Res Rev 1993, 18:247-291.

7. Robinson TE, Berridge KC: The psychology and neurobiology of addiction: an incentive-sensitization view. Addiction 2000, 95(Suppl 2):S91-117.

8. Itzhak Y, Martin JL, Ali SF: Methamphetamine-induced dopaminergic neurotoxicity in mice: long-lasting sensitization to the locomotor stimulation and desensitization to the rewarding effects of methamphetamine. Prog Neuropsychopharmacol Biol Psychiatry 2002, 26:1177-1183.

9. Bjorklund A, Lindvall O: In Chemical Neuroanatomy: Classical Transmitters in the CNS, Part 1.Edited by: Bjorklund A, Lindvall. Elsevier, Amsterdam; 1984:55-122.

10. Kelley AE, Christopher GL, Gauthier AM: Induction of oral stereotypy following amphetamine microinjection into a discrete subregion of the striatum. Psychopharmacology 1988, 95:556-559.

11. Marshall JF, Ruskin DN, LaHoste GJ: D1/D2 dopamine receptor interactions in basal ganglia functions. In the dopamine receptors. Edited by: Neve KA, Neve RL. New Jersey: Humana Press; 1997:193-219.

12. Jadhav SA, Gaikwad RV, Gaonkar RK, Thorat VM, Gursale SC, Balsara JJ: Dose-dependent response of central dopaminergic systems to buspirone in mice. Indian J Exp Biol 2008, 46:704-714.

13. Beaulieu J, Gainetdinov RR: The physiology, signaling, and pharmacology of dopamine receptors. Pharmacol Rev 2011, 63:182-217.

14. Abramow-Newerly M, Roy AA, Nunn C, Chidiac P: There RGS proteins have a signaling complex; interactions between RGS proteins and GPCRs, effectors, and auxiliary proteins. Cell Signal 2006, 18:579-591.

15. Burchett SA: Psychostimulants, madness, memory, and RGS proteins? Neuromol Med 2005, 7:101-127.

16. Schwendt M, McGinty JF: Regulator of G-protein signaling 4 interacts with metabotropic glutamate receptor subtype 5 in rat striatum: relevance to amphetamine behavioral sensitization. J Pharmacol Exper Therap 2007, 323:650-657.

17. Braun AR, Chase TN: Behavioral effects of chronic exposure to selective D1 and D2 dopamine receptor agonists. Eur J Pharmacol 1988, 147:441-451

18. Rouillard C, Bedard P, Falardeau P, DiPaolo T: Repeated stimulation of D1 dopamine receptors increases the circling response to bromocriptine in rats with a 6-OHDA lesion. Eur J Pharmacol 1988, 157:125-133.

19. Xiao-Da Z, Guo-Zhang J: Enhanced stereotypic behavior by chronic treatment with bromocriptine accompanies increase of D1 receptor binding. Life Sci 1988, 42:1841-1845. 
20. Parenti M, Flauto C, Parati E, Vescovi A, Groppetti A: Differential effect of repeated treatment with L-dopa on dopamine-D1 or D2 receptors. Neuropharmacology 1986, 25:331-334.

21. Le Merrer J, Becker JA, Befort K, Kieffer BL: Reward processing by the opioid system in the brain. Physiol Rev 2009, 89:1379-1412.

22. Trujillo KA, Belluzzi JD, Stein L: Naloxone blockade of amphetamine place preference conditioning. Psychopharmacology (Berlin) 1991, 104:265-274

23. Bals-Kubik R, Ableitner A, Herz A, Shippenberg TS: Neuroanatomical sites mediating the motivational effects of opioids as mapped by conditioned place preference paradigm in rats. J Pharmacol Exp Ther 1993, 264:489-495.

24. Suzuki T, Mori T, Tsuji M, Misawa M, Nagase H: The role of the delta-opioid receptor subtypes in cocaine and methamphetamine induced place preferences. Life SCi 1994, 55:L339-L344.

25. Knapp RJ, Malatynska E, Collins N, Fang L, Wang JY, Hruby VJ, Roeske WR, Yamamura HI: Molecular biology and pharmacology of cloned opioid receptors. The FASEB J 1995, 9:516-525.

26. Wang JQ, McGinty JF: Differential effects of D1 and D2 dopamine receptor antagonists on acute amphetamine- or methamphetamineinduced up-regulation of zif/268 mRNA expression in rat forebrain. J Neurochem 1995, 65:2706-2715.

27. Hodler C, Paquet B, Gilbert F, Drolet G, Levesque D, Rouillard C: Role of endogenous enkephalin and dynorphin in amphetamine induced behavioral sensitization [abstract]. Society of Neuroscience 35th Annual Meeting, Washington, DC 2005, 1029.7.

28. Shen X, Purser C, Tien LT, Chiu CT, Paul IA, Baker R, Loh HH, Ho IK, Ma T: muOpioid receptor knockout mice are insensitive to methamphetamineinduced behavioral sensitization. J Neurosci Res 2010, 88:2294-2302.

29. Loh HH, Liu HC, Cavalli A, Yang W, Chen YF, Wei LN: $\mu$-opioid receptor knockout in mice: effects on ligand-induced analgesia and morphine lethality. Brain Res Mol Brain Res 1998, 54:321-326.

30. Tien L, Ho IK, Ma T: Methamphetamine-induced expression of zif268 mRNA is prevented by haloperidol in mice lacking mu-opioid receptor. Neurotoxicology 2010, 31:326-330.

31. Costall B, Naylor RJ, Olley JE: Substantia nigra and stereotyped behavior. Eur J Pharmacol 1972, 18:95-106.

32. Qian Y, Hitzemann B, Hitzemann R: D1 and D2 dopamine receptor distribution in the neuroleptic nonresponsive and neuroleptic responsive lines of mice, a quantitative receptor autoradiographic study. J Pharmacol Exp Ther 1992, 261:341-348.

33. Ongali B, Ase AR, Hebert C, Amdiss F, Reader TA: Dopamine D1 and D2 receptors in the forebrain of dystonia musculorum mutant mice: an autoradiographic survey in relation to dopamine contents. Synapse 2000, 37:1-15

34. Przewlocka B, Lason W, Przewlocki R: The effect of chronic morphine and cocaine administration on the Gas and Gao protein messenger RNA levels in the rat hippocampus. Neuroscienc 1994, 63:1111-1116.

35. Tervonen T, Kerman K, Oostra BA, Castre'n M: Rgs4 mRNA expression is decreased in the brain of Fmr1 knockout mouse. Molecular Brain Research 2005, 133:162-165.

36. Tien $L T$, Ho IK, Loh HH, Ma T: Role of mu-opioid receptor in modulation of preproenkephalin mRNA expression and opioid and dopamine receptor binding in methamphetamine-sensitized mice. J Neurosci Res 2007, 85:673-680.

37. Robinson TE, Berridge KC: The psychology and neurobiology of addiction: an incentive-sensitization view. Addiction 2000, 95(Suppl 2):S91-117.

38. Chiu C, Ma T, Ho IK: Methamphetamine-induced behavioral sensitization in mice: alterations in mu-opioid receptor. J Biomedical Sci 2006, 13:797-811.

39. Lin CW, Bianchi BA, Miller TR, Stashko MA, Wang SS, Curzon P, Bednarz L, Asin KE, Britton DR: Persistent activation of the dopamine D1 receptor contributes to prolonged receptor desensitization: studies with A-77636. J Pharmacol Exper Therap 1996, 276:1022-1029.

40. Hyman SE, Malenka RC, Nestler EJ: Neural mechanisms of addiction: the role of reward-related learning and memory. Annu Rev Neurosci 2006, 29:565-598.

41. Gerfen CR, Engber TM, Mahan LC, Susel Z, Chase TN, Monsma FJ Jr, Sibley DR: D1 and D2 dopamine receptor-regulated gene expression of striatonigral and striatopallidal neurons. Science 1990, 250:1429-1432.

42. Chatoff EH, Marck BT, Matsumoto AM, Dorsa DM, Palmiter RD: Induction of stereotypy in dopamine-deficient mice requires striatal D1 receptor activation. PNAS 2001, 98:10451-10456.
43. Tang F, Costa E, Schwarts JP: Increase of proenkephalin mRNA and enkephalin content of rat striatum after daily injection of haloperidol for 2-3 weeks. Proc Natl Acad Sci USA 1983, 80:3841-3844.

44. Mocchetti I, Naranjo JR, Costa E: Regulation of striatal enkephalin turnover in rats receiving antagonists of specific dopamine receptor subtypes. $J$ Pharmacol Exp Ther 1987, 241:1120-1124.

45. Sunahara RK, Guan HC, O'Dowd BF, Seeman P, Laurier LG, Ng G, George SR, Torchia J, Van Tol HH, Niznik HB: Cloning of the gene for a human dopamine D5 receptor with higher affinity for dopamine than D1. Nature 1991, 350:614-619.

46. Zhang K, Tarazi Fl, Campbell A, Baldessarini RJ: GABA(B) receptors: altered coupling to $\mathrm{G}$-proteins in rats sensitized to amphetamine. Neuroscience 2000, 101:5-10.

47. Mirnics K, Middleton FA, Stanwood GD, Lewis DA, Levitt P: Disease-specific changes in regulator of G-protein signaling 4 (RGS4) expression in schizophrenia. Mol Psychiatry 2001, 6:293-301.

48. Young LT, Li PP, Kish SJ, Siu KP, Kamble A, Hornykiewicz O, Warsh JJ: Cerebral cortex Gs alpha protein levels and forskolin-stimulated cyclic AMP formation are increased in bipolar affective disorder. J Neurochem 1993, 61:890-898.

49. Butkerait $P$, Friedman E: Repeated reserpine increases striatal dopamine receptor and guanine nucleotide binding protein RNA. J Neurochem 1993, 60:566-571.

50. Hollinger S, Hepler JR: Cellular regulation of RGS proteins: Modulators and integrators of $\mathrm{G}$ protein signaling. Pharmacol Rev 2002, 54:527-559.

51. Hooks SB, Waldo GL, Krumins AM, Harden TK: RGS6, RGS7, RGS9, and RGS11 stimulate GTPase activity of $G_{i}$ family G-proteins with differential selectivity and maximal activity. JBC 2003, 278:10087-10093.

52. Ross EM, Wilkie TM: GTPase-activating proteins (GAPs) for heterotrimeric $\mathrm{G}$ proteins: regulators of $\mathrm{G}$ protein signaling (RGS) and RGS-like proteins. Annu Rev Biochem 2000, 69:795-827.

53. Gold SJ, Ni YG, Dohlman HG, Nestler EJ: Regulators of G-protein signaling (RGS) proteins: region-specific expression of nine subtypes in rat brain. $J$ Neurosci 1997, 17:8024-8037.

54. Grafstein-Dunn E, Kathleen HY, Cockett MI, Khawaja XZ: Regional distribution of regulators of G-protein signaling (RGS) 1, 2, 13, 14, 16, and GAIP messenger ribonucleic acids by in situ hybridization in rat brain. Molecular Brain Research 2001, 88:113-123.

55. Taymans JM, Leysen JE, Langlois X: Striatal gene expression of RGS2 and RGS4 is specifically mediated by dopamine D1 and D2 receptors: Clues for RGS2 and RGS4 functions. J Neurochem 2003, 84:1118-1127.

56. Burchett SA, Bannon MJ, Grannenab JG: RGS expression in rat striatum: modulation by dopamine receptors and effects of repeated amphetamine administration. J Neurochem 1999, 72:1529-1533.

57. Burchett SA, Volk ML, Bannon MJ, Granneman JG: Regulators of G protein signaling: rapid changes in mRNA abundance in response to amphetamine. J Neurochem 1998, 70:2216-2219.

58. Bishop GB, Cullinan WE, Curran E, Gustein HB: Abused drugs modulate RGS4 mRNA levels in rat brain: comparison between acute drug treatment and a drug challenge after chronic treatment. Neurobiol Dis 2002, 10:334-343.

59. Schwendt M, Gold SJ, McGinty JF: Acute amphetamine down-regulates RGS4 mRNA and protein expression in rat forebrain: distinct roles of D1 and D2 dopamine receptors. J Neurochem 2006, 96:1606-1615.

60. Schwendt M, Hearing MC, See RE, McGinty JF: Chronic cocaine reduces RGS4 mRNA in rat prefrontal cortex and dorsal striatum. NeuroReport 2007, 18:1261-1265.

61. Schwendt M, MCGinty JF: Regulator of G-protein signaling 4 interacts with mGluR5 receptors in rat striatum: Relevance to amphetamine behavioral sensitization. J Pharmacol Exper Therap 2007, 323:650-657.

62. Gonzalez-Nicolini V, McGinty JF: Gene expression profile from the striatum of amphetamine-treated rats: a cDNA array and in situ hybridization histochemical study. Gene Expr Patterns 2002, 1:193-198.

63. Girault JA, Valjent E, Caboche J, Herve D: ERK2: a logical AND gate critical for drug-induced plasticity? Curr Opin Pharmacol 2007, 7:77-85.

doi:10.1186/1423-0127-18-83

Cite this article as: Park et al:: Methamphetamine-induced changes in the striatal dopamine pathway in $\mu$-opioid receptor knockout mice. Journal of Biomedical Science 2011 18:83. 